\title{
The Effect of Lutein on Ischemia-reperfusion-induced Vasculitic Neuropathic Pain and Neuropathy in Rats
}

\author{
SAHIN YUCELI ${ }^{1}$, GULCE NAZ YAZICI ${ }^{2}$, RENAD MAMMADOV ${ }^{3}$, HALIS SULEYMAN $^{3}$ and SELCUK OZDOGAN ${ }^{4}$ \\ ${ }^{1}$ Department of Neurosurgery, Neon Hospital, Erzincan, Turkey; \\ ${ }^{2}$ Department of Histology and Embryology, Erzincan Binali Yildirim \\ University School of Medicine, Erzincan, Turkey; \\ ${ }^{3}$ Department of Pharmacology, Erzincan Binali Yildirim University School of Medicine, Erzincan, Turkey; \\ ${ }^{4}$ Department of Neurosurgery, Adatıp Hospital, Istanbul, Turkey
}

\begin{abstract}
Background/Aim: Neuropathic pain and neuropathy is commonly seen after ischemia-reperfusion injuries. Our aim was to evaluate the effect of lutein on ischemia-reperfusion (I/R)induced vasculitic neuropathic pain and neuropathy in rats. Materials and Methods: An hour before anesthesia, 6 Albino Wistar male rats with I/R were orally administered with $1 \mathrm{mg} / \mathrm{kg}$ lutein (LIR group). Two groups of 6 such rats who underwent surgery were provided with $0.5 \mathrm{ml}$ distilled water (as solvent) either via oral administration (SIR group) or by gavage (sham group or $S G)$. One hour following the administration, the later femoral arteries of the LIR and SIR rats were closed using a sterile silk thread and ischemia was induced in the sciatic nerve for $4 \mathrm{~h}$, followed by reperfusion for $24 \mathrm{~h}$. The femoral artery of the $S G$ group was not closed with suture. Next, $1 \mathrm{mg} / \mathrm{kg}$ lutein was re-administered only to the LIR group for $1 \mathrm{~h}$, followed by measurement of the paw pain thresholds by the Basile Algesimeter. The levels of malondialdehyde (MDA), total glutathione (tGSH), nuclear factor- $k B(N F-k B)$, and tumor necrosis factor-alpha $(T N F-\alpha)$ in the sciatic nerve tissues were measured, and the tissues were histopathologically examined. Results: We found that the MDA, NF-kB, and TNF- $\alpha$ levels were higher and the $t G S H$ level was lower in the SIR group relative to those in the LIR group, and the differences were statistically significant. Significant histopathological damage was noted in the SIR group, whereas the LIR group demonstrated protection from oxidative damage. Conclusion: Lutein is potentially useful in the treatment of I/R-related neuropathy and neuropathic pain.
\end{abstract}

This article is freely accessible online.

Correspondence to: Selcuk Ozdogan, Department of Neurosurgery, Adatıp İstanbul Private Hospital, Yenisehir, Kardelen sk. No. 2, 34000 Pendik/Istanbul, Turkey. Tel: +90 5067637173, e-mail: drselcukozdogan@gmail.com

Key Words: Sciatic nerve, lutein oxidative injury.
Ischemia-reperfusion ( $\mathrm{I} / \mathrm{R})$ injury is a complex pathological process that begins with a decrease in the tissue oxygen levels, followed by the production of free oxygen radicals, resulting in an inflammatory response (1). The I/R event in the vascular and nervous systems have been documented with an increasing ischemic and vasculitic neuropathic pain that clinically resembles the complex regional pain syndrome (2). In isolated vasculitis, a form of vasculitic neuropathy of the peripheral nervous system, medium- and small-size vessels in peripheral nerves are usually affected (3). The incidence of vasculitic neuropathies is greater in the lower extremities and causes severe pain (4). Some reports assert that neuropathy may be the first or even the only indicator of vasculitis (5).

An $\mathrm{I} / \mathrm{R}$ event is also known to induce significant damages to the nerve cells as well as to the internal organs (6). Reportedly, the I/R process induces microvascular changes, which lead to structural and functional disorders of nerve tissues (7). The pathophysiology of I/R injury consists of a complex event that involves the obstruction of the capillaries, immune cell activation, free oxygen radical (FOR) production, lipid peroxidation (LPO), and increased antioxidant expenditure $(8,9)$. The together, these data suggest that drugs with antioxidant and anti-inflammatory properties may be useful in the treatment of vasculitic neuropathic pain.

Lutein $\left(\mathrm{C}_{40} \mathrm{H}_{56} \mathrm{O}_{2}\right)$ is a known antioxidant and antiinflammatory tetraterpenoid (10). Lutein can inhibit the antioxidant activity inside cells by inhibiting lipid peroxidation and preventing reduction of the Glutathione (GSH) levels (11). Lutein has also been reported to possess anti-inflammatory properties (12). It has been demonstrated to protect tissues from damages caused by excessive production of nuclear factor- $\mathrm{kB}(\mathrm{NF}-\mathrm{kB})$ and tumor necrosis factor-alpha (TNF- $\alpha$ ) (13). Despite this, the effects of lutein on I/R-induced vasculitic neuropathy and neuropathic pain have not been investigated. I/R in the rat femoral artery has, however, been proposed as an experimental model of 
vasculitic peripheral neuropathy with clinically observed neuropathic pain and peripheral nerve injury (9).

In this study, we investigated the effect of lutein on I/Rinduced peripheral (sciatic nerve) vasculitic neuropathy and neuropathic pain in rats using biochemical and histopathological analysis.

\section{Materials and Methods}

A total of 18 Albino Wistar male rats (weight=275-288 g) were obtained from the Atatürk University Medical Experimental Application and Research Center (Erzurum, Turkey). All animals were housed and fed at the normal room temperature $\left(22^{\circ} \mathrm{C}\right)$ for 1 week prior to the experiment. The protocols and procedures of the animal study were approved by the local Animal Experimentation Ethics Committee (No: 77040475-641.04-E.1900086740).

Ketamin used in the experiment was obtained from Pfizer (Istanbul, Turkey), and lutein was obtained from Solgar (Leonia, NJ, USA). The rats were divided into 3 groups as follows: i) LIR group composed of I/R-induced rats treated with $1 \mathrm{mg} / \mathrm{kg}$ lutein, ii) SIR group composed of I/R-induced rats without lutein treatment, and iii) Sham group (SG) composed of rats with no $I / R$ or lutein treatment.

Experimental procedure. The surgical procedures on the rats were performed in an appropriate laboratory environment and under sterile conditions. Anesthesia was induced with $60 \mathrm{mg} / \mathrm{kg}$ ketamine hydrochloride. An hour before anesthesia, $1 \mathrm{mg} / \mathrm{kg}$ lutein was orally administered to the LIR ( $\mathrm{n}=6$ ) group, and $0.5 \mathrm{ml}$ distilled water (as solvent) was orally administered to the $\operatorname{SIR}(n=6)$ and via gavage to the SG (n=6) group. An hour after the administration of the drug and distilled water, all rats were fixed to the operating table in the supine position. The femoral and inguinal regions of the rats were shaved and sterilized with povidone-iodine solution. The right femoral arteries of the LIR, SIR, and SG rats were exposed with a skin incision made in the inguinal region. In the SG group, sutures were placed around the femoral artery of the rats without being tightened. In the LIR and SIR groups, ischemia was induced by occluding the femoral artery for $4 \mathrm{~h}$ using a silk suture (6-0) (Ethicon, New Brunswick, NJ, USA) and a slip-knot technique. At the end of this period, re-perfusion of the peripheral nerve tissues was achieved for $24 \mathrm{~h}$. The area that had opened during the reperfusion was sutured and closed using a sterile surgical thread. At the $24^{\text {th }}$ hour of reperfusion, $1 \mathrm{mg} / \mathrm{kg}$ lutein was re-administered to the LIR group, and the same volume of distilled water was administered to the SIR and SG groups. After $1 \mathrm{~h}$, the paw pain thresholds of the rats were estimated by using the Basile Algesimeter (14). Immediately after the measurement, the rats were sacrificed by administering high-dose ketamine $(120 \mathrm{mg} / \mathrm{kg})$ anesthesia, and their sciatic nerve tissues were removed, for the determination of malondialdehyde (MDA), total glutathione ( $\mathrm{tGSH}$ ), nuclear factor-kB (NF-kB), and tumor necrosis factor-alpha (TNF$\alpha)$ levels as well as for histopathological examination.

MDA analysis. The MDA assessment method was based on the one proposed by Ohkawa et al. (15). This method involves spectrophotometric assessment of the absorption of the pink complex created by a reaction between thiobarbituric acid (TBA) and MDA at high temperature $\left(95^{\circ} \mathrm{C}\right)$ and $532-\mathrm{nm}$ wavelength. The sciatic nerve tissue homogenates were centrifuged for $20 \mathrm{~min}$ at $5,000 \mathrm{~g}$, and the supernatants were applied for the determination of the amount of MDA. Next, $250 \mu \mathrm{l}$ of the homogenates were added to a mix of $100 \mu \mathrm{l}$ of $8 \%$ sodium dodecyl sulfate (SDS), $750 \mu \mathrm{L}$ of $20 \%$ acetic acid, $750 \mu \mathrm{l}$ of $0.08 \%$ TBA, and $150 \mu \mathrm{l}$ of distilled water, and were mixed into capped test tubes by pipetting. The mixture was then incubated for $60 \mathrm{~min}$ at $100^{\circ} \mathrm{C}$, after which $2.5 \mathrm{ml}$ of n-butanol was added to it and the mixture was subjected to spectrophotometric analysis. The amounts of the resultant red color were measured using 3-ml cuvettes at $532 \mathrm{~nm}$ wavelength. The MDA amounts in the samples were determined with reference to the standard graphics prepared by the analysis of the MDA stock solution that was previously prepared considering the dilution coefficients.

$t G S H$ analysis. The 5,5'-Dithiobis (2-nitrobenzoic acid) (DTNB) compound in the assessment environment is a disulfide chromogen and easily reduced by the sulfhydryl group compounds. The resultant yellow color after the reaction was spectrophotometrically assessed at $412 \mathrm{~nm}$ (16). The sciatic nerve tissue homogenates were centrifuged for $10 \mathrm{~min}$ at $12,000 \mathrm{~g}$, and the supernatants were used for the determination of the MDA level. Next, $250 \mu \mathrm{l}$ of a measuring buffer $(200 \mathrm{mM}$ Tris- $\mathrm{HCl}$, $\mathrm{pH}=8.2$ containing $0.2 \mathrm{mM}$ EDTA), $500 \mu \mathrm{l}$ of the supernatant, $100 \mu \mathrm{l}$ of DTNB, and $790 \mu \mathrm{l}$ of methanol were mixed into the capped test tubes by pipetting. The mixture was then incubated for $30 \mathrm{~min}$ at $37^{\circ} \mathrm{C}$ and subjected to spectrophotometric analysis. The amount of the resultant yellow color was determined in 3-ml quartz cuvettes at 412-nm wavelength. The GSH amounts in the samples were determined with reference to the standard graphics using the GSH stock solution previously prepared considering the dilution coefficients.

$T N F-\alpha$ and $N F-k B$ analysis. The tissue-homogenate levels of NF$\mathrm{KB}$ and TNF- $\alpha$ were determined using the rat-specific sandwich enzyme-linked immunosorbent assay, Rat Nuclear Factor-Kappa B ELISA immunoassay kit (Cat. No: 201-11-0288; Shanghai Sunred Biological Technology Co. Ltd., Shanghai, PR China) and Rat Tumor Necrosis Factor a ELISA kits (Cat no: YHB1098Ra; Shanghai Sunred Biological Technology Co. Ltd., Shanghai, PR China). The analyses were performed according to the manufacturers' instructions. Briefly, monoclonal antibodies specific for either rat NF-kB or rat TNF- $\alpha$ were coated onto the wells of micro plates. The tissue homogenate, standards, and biotinylated specific monoclonal antibody and streptavidin-HRP were pipetted into these wells and then incubated at $37^{\circ} \mathrm{C}$ for $60 \mathrm{~min}$. After washing, the chromogen reagent $\mathrm{A}$ and chromogen reagent $\mathrm{B}$ were added to the wells and incubated at $37^{\circ} \mathrm{C}$ for $10 \mathrm{~min}$. These reagents produce a color after reacting with the bound enzyme. The reaction is then stopped by adding a stop solution. The intensity of the colored product produced is directly proportional to the concentration of the NF-kB and TNF- $\alpha$ present in the original specimen obtained from the rats. At the end of the experiment, the wells contents were read at $450 \mathrm{~nm}$.

Histopathological examination. All the tissue samples were first fixed in a $10 \%$ formaldehyde solution and then assessed by light microscopy. Following the identification process, the tissue samples were washed under tap water in cassettes for $24 \mathrm{~h}$. The samples were then treated with a conventional grade of alcohol $(70 \%, 80 \%$, 
$90 \%$, and $100 \%$ ) to remove the water contained within the tissues Next, the tissues were passed through xylol, embedded in paraffin, cut into 4-5 $\mu$-thick sections, and stained with hematoxylin-eosin. Their images were captured following assessment by the Olympus DP2-SAL firmware program (Olympus ${ }^{\circledR}$ Inc. Tokyo, Japan). Histopathological analyses were performed by a pathologist blinded to the study groups.

Statistical analyses. All data were subjected to the Kruskal-Wallis test using the SPSS version 18.0 software (IBM Corporation, Armonk, NY, USA). The differences among the groups were obtained using Wilcoxon rank-sum tests with Bonferroni corrections. Statistical significance was set at $p$-Value $=0.05$. The results were expressed as the mean \pm standard error of the mean (SEM).

\section{Results}

The sciatic nerve tissues showed statistically significant decrease in the pain threshold of the rat paw in the LIR group in comparison to the SIR group $(p<0.0001$; Table I).

The amount of MDA increased in the sciatic nerve tissues of the rats in the SIR group (Figure 1), while lutein could significantly suppress the MDA level increase in the sciatic nerve tissues after the SIR procedure $(p<0.0001)$. Conversely, the amount of tGSH decreased in the sciatic nerve tissues of the rats in the SIR group, while lutein could significantly prevent I/R-induced tGSH decrease in the sciatic nerve tissues $(p<0.0001)$.

The discontinuation of the blood flow from the femoral artery to the sciatic nerve tissues increased both TNF- $\alpha$ and NF-kB levels in the nerve tissues; however, lutein could significantly inhibit the increase of TNF- $\alpha$ and NF-kB levels in the nerve tissues after SIR $(p<0.0001$; Figure 2).

Histopathological findings. Histological examination of the SG sciatic nerve tissues revealed that the nerve structure was normal, the axons were surrounded by myelin sheaths and were located centrally, and the Schwann cell nucleuses were normal in shape. The middle layer of the connective tissue investments, the perineurium, properly covered each bundle of nerve fiber fascicles and its thickness was also normal (Figure 3). In the SIR group, the myelinated nerve fibers were swollen, and the myelin sheath surrounding the axons lost their central position. Dislocations and irregularities were noted in the nevre fascicules. The degenerated and distorted myelin sheaths attracted attention. The Schwann cells generally demonstrated hypertrophy and hyperplasia. The blood vessels were mostly congested. The perineurium was quite thick and revealed an irregular structure (Figures 4 and 5). In the LIR group, the myelinated nerve fibers were generally normal in sight and axons located centrally. The Schwann cells were normal in shape, the degeneration of the myelin sheats had vanished, and the blood vessels also appeared normal. In addition, all connective tissue structuring was normal (Figure 6).
Table I. The effect of lutein on ischemia-reperfusion $(I / R)$ induced vasculitic neuropathic pain.

\begin{tabular}{lcc}
\hline Group & $\begin{array}{c}\text { Pain threshold (gr) } \\
1^{\text {st }} \text { hour }\end{array}$ & $\begin{array}{c}\text { Analgesia activity (\%) } \\
1^{\text {st }} \text { hour }\end{array}$ \\
\hline SIR & $5.7 \pm 0.5$ & \\
LIR & $19.5 \pm 1.2$ & 70.8 \\
SG & $29 \pm 1.2$ & 80.4 \\
\hline
\end{tabular}

LIR: Lutein ischemia-reperfusion; SIR: ischemia-reperfusion with no lutein; SG: sham group.

\section{Discussion}

In this study, the effect of lutein on I/R-induced sciatic nerve neuropathic pain and vasculitic neuropathy were examined in rats by biochemical and histopathological examinations. Our results revealed that the application of the LIR procedure to the sciatic nerve tissues significantly reduced the pain threshold in the paw of the experimental rats. These findings suggest that hyperalgesia develops in the region innervated by the sciatic nerve. Moreover, it has previously been emphasized that the application of vascular occlusion or an $\mathrm{I} / \mathrm{R}$ event to nerve tissues results in vasculitic neuropathic pain, which is clinically similar to the regional pain syndrome (2).

Chung et al., have employed the same approach as ours to evaluate the peripheral neuropathic pain and found that neuropathic pain and an experimental model of vasculitic peripheral neuropathy both develop after the discontinuation of femoral arterial blood flow $(9,17)$. Neuropathic pain manifests as spontaneous pain, such as i) hyperalgia, ii) allodynia, iii) pain independent of stimulus, or iv) pain induced by stimulus (pain hypersensitivity) after the peripheral nerve damage. Vasculitic peripheral neuropathic pain manifests as an acute pain arising from ischemic injury of the peripheral nerves $(9,18)$. Our experimental results together with the literature data indicate that the application of the I/R procedure to sciatic nerve tissues may result in neuropathy and neuropathic pain.

In the literature, the pathophysiology of peripheral nerve $\mathrm{I} / \mathrm{R}$ tissue damage has been associated with increased FOR production (19). In fact, the application of the reperfusion procedure to the ischemic tissues is considered as a pathophysiological event separate from ischemic injury. It has been long argued that the reasons that initiate reperfusion injury include superoxide radicals, hydrogen peroxide, and hydroxyl radicals (20). In our study, an increase in the MDA level and a decrease in the tGSH level were recorded in the sciatic nerve tissues of rats treated with I/R; these results are consistent with those reported in the literature. It has been reported that the MDA level increases and the GSH level 

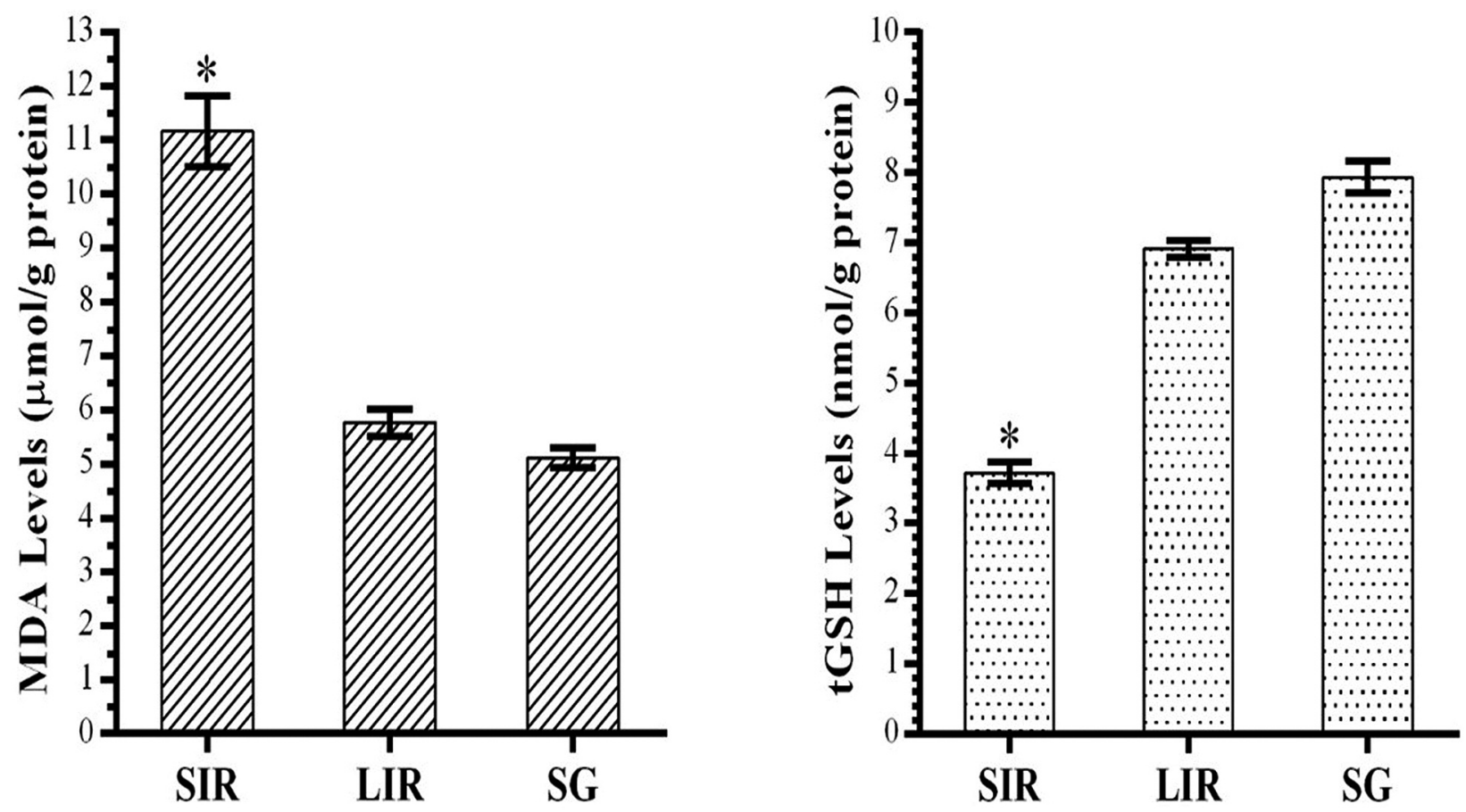

Figure 1. Malondialdehyde (MDA) and total glutathione (tGSH) levels of SIR, LIR and SG groups. *p<0.0001, according to LIR and SG groups $(n=6)$. LIR: Lutein ischemia-reperfusion; SIR: ischemia-reperfusion with no lutein; SG: sham group.
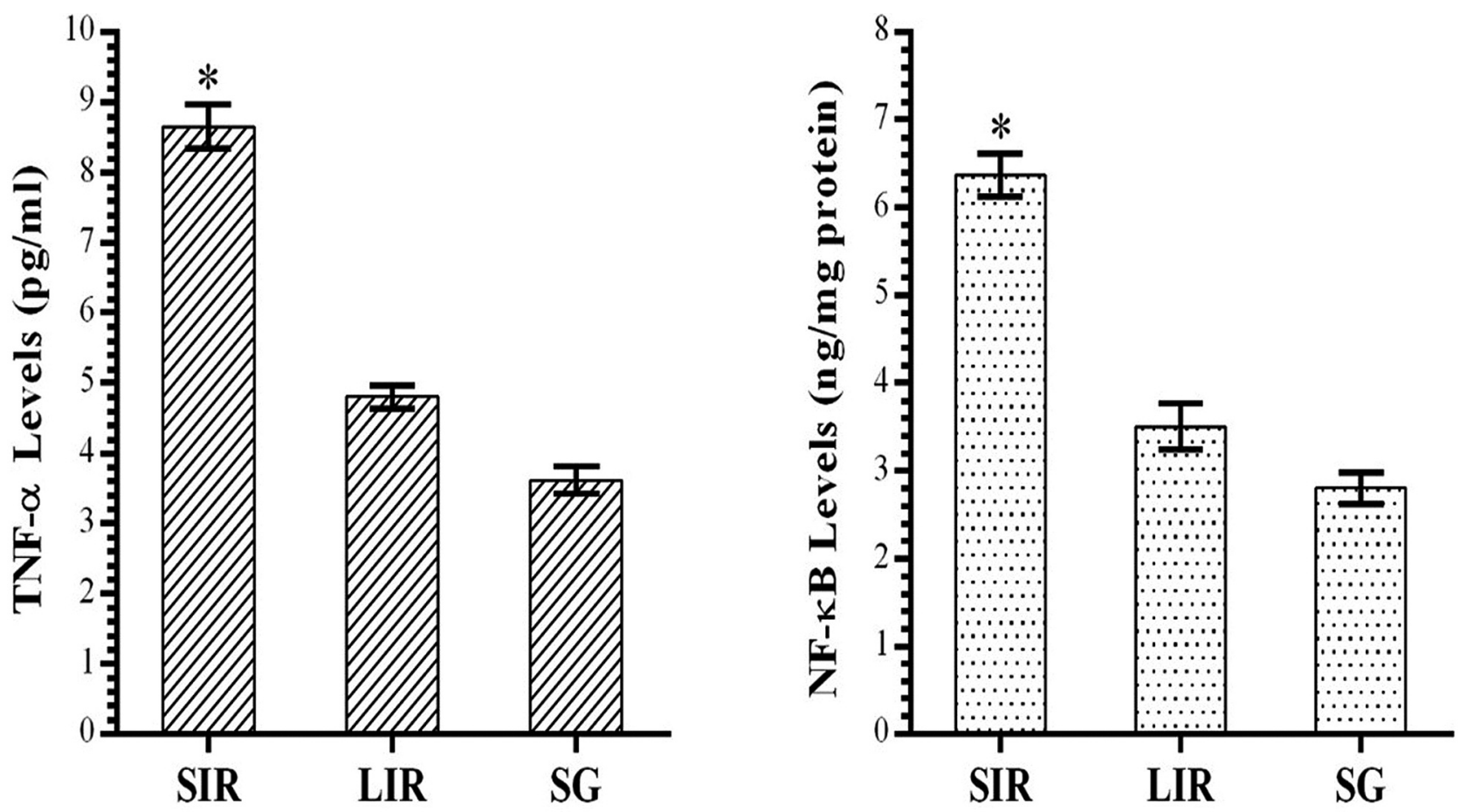

Figure 2. Nuclear factor- $k B(N F-k B)$ and tumor necrosis factor-alpha TNF- $\alpha$ levels of SIR, LIR and SG groups. ${ }^{*} p<0.0001$, according to LIR and $S G$ groups (n=6). LIR: Lutein ischemia-reperfusion; SIR: ischemia-reperfusion with no lutein; SG: sham group. 


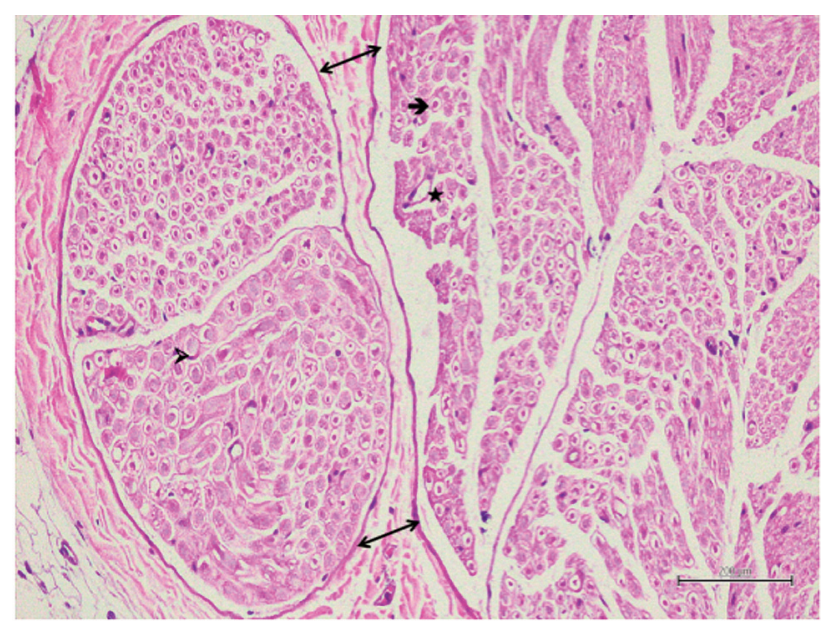

Figure 3. Hematoxylin-eosin staining in sciatic nerve tissue in the control group. $\rightarrow:$ Myelinated axon, $>$ : Schwann cell nucleus, $\star$ : blood vessel, $\leftrightarrow:$ perineurium, Magnification: $\times 200$.

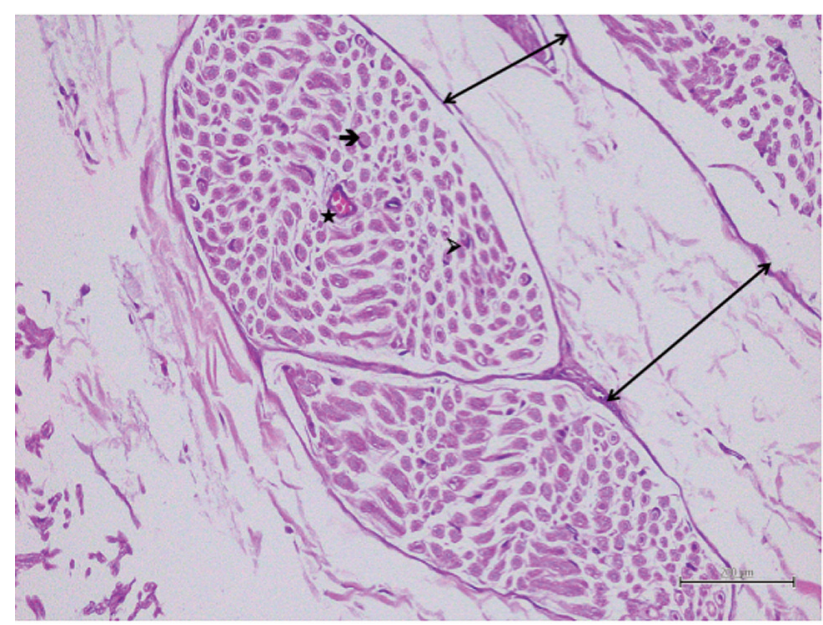

Figure 5. Hematoxylin-eosin staining in sciatic nerve tissue in the ischemialreperfusion group. $\rightarrow:$ Myelinated axon, $>$ : hypertrophic and hyperplasic Schwann cell nucleus, $\star$ : blood vessel, $\leftrightarrow:$ perineurium, Magnification: $\times 200$.

decreases under oxidative stress in parallel with an increase in FOR production (21). It has also been documented that FORs cause the formation of toxic products, such as MDA, by oxidizing lipids found in the cell membrane (22). MDA is an oxidant product that increases and exacerbates oxidative damage (23). We attributed the reason for decreasing tGSH to FOR expenditure due to the overproduction of FORs. Furthermore, we noted that if the antioxidants are insufficient in neutralizing the oxidants, the

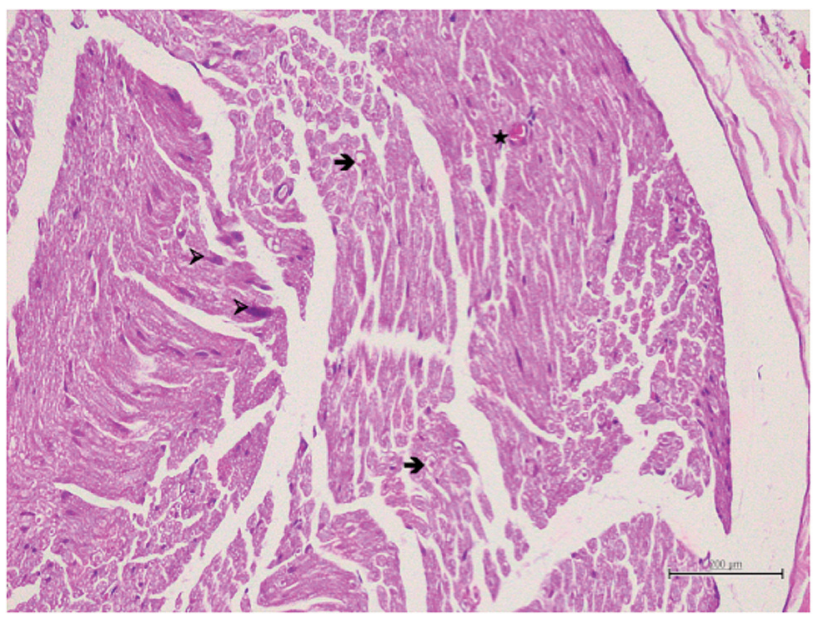

Figure 4. Hematoxylin-eosin staining in sciatic nerve tissue in the ischemia/reperfusion group. $\rightarrow$ : Degenerated myelinated axon, $>$ : hypertrophic and hyperplasic Schwann cell nucleus, $\star$ : dilated and congested blood vessel, Magnification: $\times 200$.

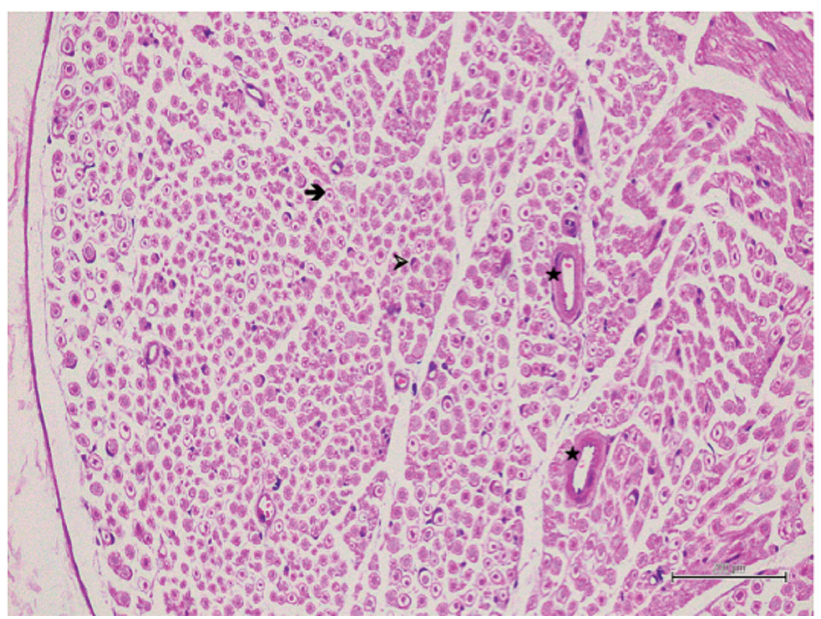

Figure 6. Hematoxylin-eosin staining in sciatic nerve tissue in the ischemia/reperfusion + lutein group. $\rightarrow:$ Myelinated axon, $>:$ normal Schwann cell nucleus, $\star$ : normal blood vessel, Magnification: $\times 200$.

oxidant/antioxidant balance gets disrupted in favor of the oxidants; this inference based on our experimental results is consistent with the literature (21).

The application of $\mathrm{I} / \mathrm{R}$ as found to increase the production of proinflammatory cytokines, such as TNF- $\alpha$, as well as transcription factors regulating proinflammatory signaling, such as NF-kB, in the sciatic nerve tissues. The inhibition of TNF- $\alpha, N F-k B$, and other proinflammatory cytokine-related pathways is accepted as a possible target in the treatment of 
inflammation and neuropathic pain (9). During neuronal inflammation, the activation of $\mathrm{NF}-\mathrm{kB}$ regulates the expression of various proinflammatory mediators, resulting in nerve damage (24). Past studies have demonstrated that the NF- $\mathrm{kB}$ expression in the nerve tissues during the femoral artery-associated sciatic nerve $\mathrm{I} / \mathrm{R}$ event induces a neuroinflammatory response. In addition, an I/R event can lead to vasculitic peripheral neuropathy, and the expression of TNF- $\alpha$ and NF-kB are involved in vasculitic neuropathic pain (9). In agreement with the literature, our results indicate that the I/R procedure induces proinflammatory signaling production in sciatic nerve tissues.

Lutein was examined for its effect on neuropathic pain caused by sciatic nerve I/R and was found to significantly prevent the pain threshold reduction in the rat paws. There is no report in the literature on the effect of lutein on the sciatic nerve vasculitic damage and in the induction of neuropathic pain. However, some past studies suggest that lutein can prevent neuropathic pain. For instance, Tan et al., have reported that lutein can avoid brain injury caused by cytokine-induced inflammation and FOR-induced oxidative stress (25). Furthermore, it has been reported that lutein protects the optic nerve tissues from damage from ethambutol and isoniazid via the inhibition of the MDA, TNF- $\alpha$ production and tGSH consumption (26). Our results are consistent with reports of the protective effect of lutein in tissues damaged from the overproduction of NF- $\mathrm{kB}$ and TNF- $\alpha$ (13). Therefore, we believe that the analgesic effect of lutein can be attributed to FOR production and proinflammatory cytokine inhibition.

In our study, the findings of the biochemical examinations were perfectly consistent with those of histopathological examinations. In the sciatic nerve tissues of the SIR group, the MDA, NF-kB, and TNF- $\alpha$ levels were high and the tGSH level was low, while significant severe pathological findings were recorded in the myelinated nerve fibers, myelin sheath, nerve fascicles, Schwann cells, perineurium, and blood vessels. As per past reports, the histopathological damages occurred during the I/R process, such as neuronal edema and nerve fiber degeneration, are associated with FORs $(7,19)$. Some past reports state that ischemia develops after blood vessel occlusion due to vasculitis, and histopathological changes occur in the nerve tissues, which support our results $(18,27)$. Our histopathological findings of increased FOR and proinflammatory mediator production conforms to those reported elsewhere $(28,29)$. In addition, a study by Karakurt et al., have also demonstrated the antioxidant activity of lutein and its inhibitory effect on proinflammatory cytokine production (30).

In conclusion, our biochemical and histopathological results demonstrate that significant damage develops in the sciatic nerve tissues following a temporary occlusion of the femoral arteries. This sciatic nerve $\mathrm{I} / \mathrm{R}$ injury caused regional hyperalgesia. Lutein could significantly reduce the pain resultant from the sciatic nerve I/R injury, prevent the increase in the levels of oxidative and proinflammatory markers. The results of our experimental study suggest that lutein may be useful in the treatment of I/R sciatic nerve injury.

\section{Conflicts of Interest}

The Authors have no conflicts of interest to declare regarding this study.

\section{Authors' Contributions}

SY was responsible for study design was done by SY, data collection by SY, RM, and HS; experimental procedures by RM and HS; data analysis by GNY and SO; histological examination by GNY; statistical analyses by HS; writing manuscript by SY and SO; final revisions by SO.

\section{References}

1 Yapca OE, Borekci B and Suleyman H: Ischemia-reperfusion damage. Eurasian J Med 45(2): 126-127, 2013. PMID: 25610264. DOI: 10.5152/eajm.2013.24

2 Muthuraman A, Ramesh M and Sood S: Ameliorative potential of montelukast on ischemia-reperfusion injury induced vasculitic neuropathic pain in rat. Life Sci 90(19-20): 755-762, 2012. PMID: 22483690. DOI: 10.1016/j.lfs.2012.03.010

3. İlhan A: Vasculiticneuropathies. TurkiyeKlinikleri J NeurolSpecial Topics 6(3): 47-55, 2013.

4 Graf J and Imboden J: Vasculitis and peripheral neuropathy. Curr Opin Rheumatol 31(1): 40-45, 2019. PMID: 30461543. DOI: 10.1097/BOR.0000000000000559

5 Demirci EBS and Özdamar SE:Vasculiticneuropathies. J Int Med Sci 1(22): 21-28, 2005.

6 Nouri M, Rahimian R, Fakhfouri G, Rasouli MR, MohammadiRick S, Barzegar-Fallah A, Asadi-Amoli F and Dehpour AR: Ipsilateral common iliac artery plus femoral artery clamping for inducing sciatic nerve ischemia/reperfusion injury in rats: a reliable and simple method. J Brachial Plex Peripher Nerve Inj 3: 27, 2008. PMID: 19102739. DOI: 10.1186/1749-7221-3-27

7 Muthuraman A, Diwan V, Jaggi AS, Singh N and Singh D: Ameliorative effects of Ocimum sanctum in sciatic nerve transection-induced neuropathy in rats. J Ethnopharmacol 120(1): 56-62, 2008. PMID: 18762236. DOI: 10.1016/j.jep.2008.07.049

8 Dröge W: Free radicals in the physiological control of cell function. Physiol Rev 82(1): 47-95, 2002. PMID: 11773609. DOI: 10.1152 physrev.00018.2001

9 Chung CY, Chang YW, Huang CJ, Wang PK, Wan HC, Lin YY and Kao MC: Vasculitic peripheral neuropathy induced by ischemia-reperfusion in the rat femoral artery involves activation of proinflammatory signaling pathway in the sciatic nerve. Neurosci Lett 656: 77-82, 2017. PMID: 28732764. DOI: 10.1016/j.neulet.2017.07.031

10 Sommerburg O, Keunen JE, Bird AC and van Kuijk FJ: Fruits and vegetables that are sources for lutein and zeaxanthin: the macular pigment in human eyes. Br J Ophthalmol 82(8): 907910, 1998. PMID: 9828775. DOI: 10.1136/bjo.82.8.907 
11 Du SY, Zhang YL, Bai RX, Ai ZL, Xie BS and Yang HY: Lutein prevents alcohol-induced liver disease in rats by modulating oxidative stress and inflammation. Int J Clin Exp Med 8(6): 8785-8793, 2015. PMID: 26309530.

12 Chung RWS, Leanderson P, Lundberg AK and Jonasson L: Lutein exerts anti-inflammatory effects in patients with coronary artery disease. Atherosclerosis 262: 87-93, 2017. PMID: 28527371. DOI: 10.1016/j.atherosclerosis.2017.05.008

13 El-Kholy AA, Elkablawy MA and El-Agamy DS: Lutein mitigates cyclophosphamide induced lung and liver injury via NF-kB/MAPK dependent mechanism. Biomed Pharmacother 92: 519-527, 2017. PMID: 28575809. DOI: 10.1016/j.biopha.2017.05.103

14 Cadirci E, Suleyman H, Hacimuftuoglu A, Halici Z and Akcay $\mathrm{F}$ : Indirect role of beta2-adrenergic receptors in the mechanism of analgesic action of nonsteroidal antiinflammatory drugs. Crit Care Med 38(9): 1860-1867, 2010. PMID: 20601862. DOI: 10.1097/CCM.0b013e3181e8ae24

15 Ohkawa $\mathrm{H}$, Ohishi $\mathrm{N}$ and Yagi $\mathrm{K}$ : Assay for lipid peroxides in animal tissues by thiobarbituric acid reaction. Anal Biochem 95(2): 351-358, 1979. PMID: 36810. DOI: 10.1016/00032697(79)90738-3

16 Sedlak J and Lindsay RH: Estimation of total, protein-bound, and nonprotein sulfhydryl groups in tissue with Ellman's reagent. Anal Biochem 25(1): 192-205, 1968. PMID: 4973948. DOI: 10.1016/0003-2697(68)90092-4

17 Kuyrukluyıldız U, Küpeli İ, Bedir Z, Özmen Ö, Onk D, Süleyman B, Mammadov R and Süleyman H: The Effect of Anakinra on Paclitaxel-Induced Peripheral Neuropathic Pain in Rats. Turk J Anaesthesiol Reanim 44(6): 287-294, 2016. PMID: 28058139. DOI: $10.5152 /$ TJAR.2016.02212

18 Gwathmey KG, Burns TM, Collins MP and Dyck PJ: Vasculitic neuropathies. Lancet Neurol 13(1): 67-82, 2014. PMID: 24331794. DOI: 10.1016/S1474-4422(13)70236-9

19 Muthuraman A and Sood S: Pharmacological evaluation of tacrolimus (FK-506) on ischemia reperfusion induced vasculatic neuropathic pain in rats. J Brachial Plex Peripher Nerve Inj 5: 13, 2010. PMID: 20529260. DOI: 10.1186/1749-7221-5-13

20 Babbs CF: Reperfusion injury of postischemic tissues. Ann Emerg Med 17(11): 1148-1157, 1988. PMID: 3056129. DOI: 10.1016/s0196-0644(88)80060-x

21 Suleyman H, Gül V and Erhan E:Oxidative stress and tissue damage.Erzincan Med J1: 1-4, 2018.
22 Kisaoglu A, Borekci B, Yapca OE, Bilen H and Suleyman H: Tissue damage and oxidant/antioxidant balance. Eurasian J Med 45(1): 47-49, 2013. PMID: 25610248. DOI: 10.5152/eajm.2013.08

23 Goulart M, Batoréu MC, Rodrigues AS, Laires A and Rueff J: Lipoperoxidation products and thiol antioxidants in chromium exposed workers. Mutagenesis 20(5): 311-315, 2005. PMID: 15985443. DOI: 10.1093/mutage/gei043

24 Martini R and Willison H: Neuroinflammation in the peripheral nerve: Cause, modulator, or bystander in peripheral neuropathies? Glia 64(4): 475-486, 2016. PMID: 26250643. DOI: 10.1002/glia. 22899

25 Tan D, Yu X, Chen M, Chen J and Xu J: Lutein protects against severe traumatic brain injury through anti-inflammation and antioxidative effects via ICAM-1/Nrf-2. Mol Med Rep 16(4): 4235-4240, 2017. PMID: 28731190. DOI: 10.3892/mmr.2017.7040

26 Karakurt Y, Süleyman H, Keskin Cimen F, Tasli G, Ucak T, Icel $\mathrm{E}$ and Kurt N: The effects of lutein on optic nerve injury induced by ethambutol and isoniazid: an experimental study. Cutan Ocul Toxicol 38(2): 136-140, 2019. PMID: 30362367. DOI: 10.1080/15569527.2018.1539010

27 Ogata K: [Vasculitic peripheral neuropathies: Clinical features and diagnostic laboratory tests]. Brain Nerve 68(3): 205-211, 2016. PMID: 27001769. DOI: $10.11477 / \mathrm{mf} .1416200379$

28 Kawamura N, Schmeichel AM, Wang Y, Schmelzer JD and Low PA: Multiple effects of hypothermia on inflammatory response following ischemia-reperfusion injury in experimental ischemic neuropathy. Exp Neurol 202(2): 487-496, 2006. PMID: 16934252. DOI: 10.1016/j.expneurol.2006.07.012

29 Nukada H, van Rij AM, Packer SG and McMorran PD: Pathology of acute and chronic ischaemic neuropathy in atherosclerotic peripheral vascular disease. Brain 119 (Pt 5): 1449-1460, 1996. PMID: 8931570. DOI: 10.1093/brain/119.5.1449

30 Karakurt Y, Uçak T, Tasli N, Ahiskali I, Şipal S, Kurt N and Süleyman H: The effects of lutein on cisplatin-induced retinal injury: an experimental study. Cutan Ocul Toxicol 37(4): 374-379, 2018. PMID: 29865906. DOI: 10.1080/15569527.2018.1482494

Received January 12, 2021

Revised February 7, 2021 Accepted February 11, 2021 